104 | Tropelías. Revista de Teoría de la Literatura y Literatura Comparada, número extraordinario 3 (2018) Encuesta a 18 novelistas

\title{
ENCUESTA A 18 NOVELISTAS
}

1. ¿Reconoce que se haya producido, a partir de la década del 90, alguna irrupción diferencial en la estética y/o temática en las novelas argentinas?

2. ¿Cuáles serían, a su criterio, las cinco palabras y/ o conceptos que podrían caracterizar a las novelas argentinas contemporáneas? Explique las razones.

3. ¿Con qué palabras y/o conceptos caracterizaría sus propios textos o su trabajo? Explique las razones.

\section{Autoras y autores participantes:}

Florencia Abbate

Leandro Avalos Blacha

José María Brindisi

Félix Bruzzone

Gabriela Cabezón Cámara

María Sonia Cristoff

Esther Cross

Gustavo Ferreyra

Carlos Gamerro
Aníbal Jarkowski

Martín Kohan

Alejandra Laurencich

María Rosa Lojo

María Pía López

Germán Maggiori

Natalia Moret

Ana Ojeda

Luis Sagasti 


\section{Florencia Abbate}

[Nació en 1976, en Buenos Aires. Publicó las novelas El grito (2004) y Magic Resort 2007, el volumen de cuentos Felices hasta que amanezca (2017), y los poemas de Puntos de fuga (1996), Los transparentes (2000), Neptuno (2005) y Love Song (2014). Ha realizado la antología Una terraza propia. Nuevas narradoras argentinas (2006). Es doctora en Letras por la Universidad de Buenos Aires (UBA) y se desempeña como investigadora del CONICET]

1) Debo reconocer que la Idea de «la novela argentina a partir de los 90» me resulta una abstracción difícil de abordar, probablemente debido a mi espíritu empirista y pluralista. Siento que en estos casos resulta un poco brusca la operación de subsumir lo particular a lo general, porque cada obra implica una apuesta singular. Pienso que las caracterizaciones de 'la novela argentina' (incluso esta respuesta que estoy dando) hablan más de quien las hace y del estado del campo literario y cultural en un momento determinado, que del conjunto concreto de todas las novelas que fueron publicadas durante un período. La 'pregunta del millón' es i'cuáles', de todo ese conjunto, son las novelas que se toman como referencia para sacar las conclusiones? En suma, ¿qué mira el que define, y qué no mira?

En ese sentido, para llegar a esbozar algún intento de respuesta se me ocurre hacer una pequeña digresión, e interrogarme por los modos de leer que históricamente han sido dominantes en el campo literario argentino.

Según mi memoria, desde que empecé a estudiar la narrativa argentina, hace más de veinte años, lo más común era encontrar explicaciones estructuradas en base a dicotomías, y más concretamente clasificaciones que establecían 'dos bandos'. Por ejemplo: 'Escritores de Florida' vs. 'Escritores de Boedo', 'Realistas' vs. 'Fantásticos', 'Defensores del arte por el arte' vs. 'Defensores del arte comprometido', 'Grupo de escritores de la revista Babel' vs. 'Grupo de escritores de la colección Biblioteca del Sur' (o 'Grupo Shangai' vs 'Grupo V de Vian'), 'Los que dicen hacer un trabajo con el lenguaje' vs. 'Los que dicen contar historias' (como si la narrativa no fuera ambas cosas). La otra característica de ese modo de leer, además de la estructura dicotómica, era que esos bandos estaban conformados enteramente por hombres, nombres propios masculinos que emergían como representantes de una estética o de otra.

Creo que a partir del siglo XXI comenzaron a volverse anacrónicas esas clasificaciones; y quienes escriben y publican novelas mayoritariamente ya no las alientan, ni desde los textos ni desde sus discursos como escritoras y escritores. Al parecer se terminó la Guerra Fría, y con ella murió un mundo. Y nació otro: un mundo donde la percepción se transformó al calor de los cambios introducidos por nuevas tecnologías y formas de comunicación que suponen mayor horizontalidad y diversidad, además de una enorme ampliación del acceso a la información sobre lo que ocurre más allá de las fronteras nacionales (y sobre las obras que se producen en Argentina y en el resto del mundo). En otro orden de 
cosas, con la profesionalización de la industria editorial de sellos independientes, ha habido muchas más posibilidades de publicar que en décadas anteriores, y eso también contribuye a la manifestación de una heterogeneidad de novelas refractaria a dejarse a reducir de acuerdo a dos estéticas.

La literatura ha cambiado porque la cultura ha cambiado porque la experiencia y la sensibilidad han cambiado también. Y creo que las novelas de los últimos tiempos resuenan con esos cambios de la experiencia y la sensibilidad.

Anoto entonces algunas ideas sueltas para justificar los conceptos que enumero en el siguiente punto de este cuestionario:

a. La sensación de que la propia apuesta estética no debe necesariamente situarse (ya sea en confrontación o en filiación) con respecto a referentes fuertes de la literatura nacional, puede haber contribuido a una mayor libertad que acaso se refleje en la gran diversidad estética de las novelas escritas por las generaciones que comenzaron a publicar narrativa en el siglo XXI.

b. La sensación de 'pérdida' de cierto lugar de peso en la cultura que había tenido la literatura (desplazada por otras referencias culturales y desplazada la palabra del escritor por las de otras figurasreferentes) contribuyó a la desacralización de la figura del escritor y de la literatura, y ese proceso también se puede ver en las características de la producción novelística en la actualidad.

c. Creo que en muchas novelas del siglo XXI es posible leer un mayor acercamiento a materiales del orden de la experiencia e incluso de la intimidad, y una cierta toma de distancia respecto del sesgo intelectual que había tenido en general la tradición narrativa argentina (centrada en una figura tan intelectual y tan alejada de la noción de 'experiencia' como Borges). Muchas de estas nuevas novelas parecen ser ajenas al 'pudor borgeano' y proponen materiales hasta entonces considerados no literaturizables. En cuanto a la política, a menudo aparece bajo formas que me atrevería a sintetizar con el lema 'Lo personal es político'.

d. En este contexto si se quiere más 'posmoderno', el de un campo literario donde conviven variadas y disímiles apuestas que no 'confrontan' intencionalmente entre sí (sino que más bien se reconocen en el punto en común de pertenecer todas ellas a un campo más bien marginal de la cultura actual, la literatura; más allá del juicio de valor estético que cada quien pudiera tener de la producción de cada colega), la búsqueda y el deseo de un 'afuera' parecen ser más fuertes que la intención polémica al interior del campo literario. Quizá por ello tienda a predominar un tipo de novela menos endogámica y más exogámica e híbrida, tanto en lo temático como en lo formal.

e. El siglo XXI ha tornado imposible invisibilizar el trabajo de las mujeres. Y acaso sería saludable revisar el canon narrativo argentino a la luz del reconocimiento de que ha habido una historia de invisibilización. Las escritoras son activas artífices de la historia de la novela argentina del siglo XXI. 
En las últimas décadas han emergido decenas de autoras, y se han hecho más visibles las producciones de aquellas que ya venían publicando desde décadas anteriores, e incluso de aquellas que habían fallecido sin haber accedido a un reconocimiento en el campo literario. También en sus temáticas las novelas han incorporado esta dimensión, y han aparecido personajes femeninos de una carnadura y una complejidad desconocida en el canon de la novela argentina del siglo XX (por mencionar un ejemplo, en toda la obra novelística de Saer, un escritor que admiro, no hay ni una sola narradora mujer).

2) Libertad. Desacralización. Experiencia. Exogamia. Mujeres

3) Realidad/delirio. Voces. Experiencia. Lo personal es político. Presente.

\section{Leandro Avalos Blacha}

[Nació en Quilmes, Provincia de Buenos Aires, en 1980. En 2007 su novela Berazachussetts obtuvo el Premio Indio Rico con un jurado integrado por César Aira, Daniel Link y Alan Pauls. Dos años antes había publicado su primer libro, Serialismo. En 2017 publicó la novela Malicia]

1) No sé si hay algo diferencial. Quizás sí una serie de escrituras que, de distintas formas, trabajaron esa llamada 'literatura del yo’, por un lado; y un marcado interés por géneros literarios más allá del policial, como el fantástico, la ciencia ficción, el fantasy, el terror y el cruce de todos ellos, por otro. Pero lo determinante creo que es el cambio en el mundo editorial que permite que hoy casi todo encuentre una vía de publicación. De ahí la variedad de voces y miradas que hoy circulan por una infinidad de editoriales, mientras antes lo publicable se condensaba en unas pocas opciones. ¿Se escribe más literatura de terror ahora, por ejemplo, o antes solo no llegaba a publicarse? Me preguntaría lo mismo en relación a todas las voces (y temas) que emergieron en este tiempo

2) No creo que sea posible una caracterización de la literatura argentina en esos términos. Justamente una de las riquezas es la diversidad de lo que se publica y la variedad de estéticas y enfoques. En todo caso elegiría solo una palabra como marca también de un momento del país: mujeres. Creo que son las escritoras las que están haciendo las obras más interesantes: Alejandra Zina, Fernanda García Lao, Selva Almada, Samanta Schweblin, Mariana Enríquez, Vera Giaconi, Inés Garland, por nombrar solo algunas. 
3) Tanto como lector, como a la hora de escribir me gusta la idea de la literatura 'de imaginación ' (pensando en la idea de 'l'imaginale' para los franceses). Muchas veces noto cierto menosprecio por el concepto de 'imaginación', como si fuera algo menor en una obra (pienso en la diferenciación que hace Levrero entre invención e imaginación). Elegiría también 'géneros'. Me interesa la mirada que permiten en especial el fantástico, el terror, el melodrama. Los climas, aunque a la vez creo que ninguno de mis textos se termina ajustando a uno de ellos en particular. Lo que me lleva a otra idea que está bastante presente en lo que escribo y que es el 'humor' (creo que es una de las cosas que muchas veces aparece para desarmar el funcionamiento 'serio' de los géneros en lo que escribo).

\section{José María Brindisi}

[Nació en 1969, en Buenos Aires. Después del primer volumen de cuentos, Permanece oro (1996), que obtuvo el Premio Fondo Nacional de la Artes, publicó las novelas Berlín (2001), Frenesí (2006, Premio Casa del Escritor) y Placebo (2010). Dicta cursos de Escritura Creativa en distintas instituciones del país (Museo Malba y Casa de Letras, entre otras). Ha sido colaborador de los diarios La Nación, Página 12 y Perfil. Es director general de la revista libro El Ansia, una publicación anual que en cada número se dedica a indagar el trabajo de tres autores argentinos contemporáneos]

1) No claramente. Quizá pueda notar ciertas apuestas algo más extremas, como la distorsión de la realidad que hallamos ya en las novelas tempranas de Gustavo Ferreyra, o esa suerte de realidad ampliada de novelas como Informes para Mertov, de Jorge Zentner (o las novelas de Marcelo Cohen, en particular a partir de su inmersión en ese espacio-tiempo que denominó "Delta Panorámico"; pero en su caso se trata, en términos generales, de una apuesta previa).

Veo sí algunas continuidades, más que rupturas; una suerte de neoclasicismo que por lo general se corporiza en un retorno a los géneros. Pienso en ejemplos como el de Charlie Feiling y su proyecto interrumpido y explícito de revisitar géneros (llegó a hacerlo con el policial, la novela de aventuras, el terror y el fantasy, aunque esta última novela quedó inconclusa), pero también en la explosión carnavalesca de novelas como Santería, de Leonardo Oyola, o la posterior Ceviche, de Federico Levín. Por momentos, pareciera como si determinados intentos de ruptura fuesen una reacción — una vez más - a la perfección borgeana; como si ese paradigma insuperable solo fuese capaz de generar imperfecciones, desprolijidades, ramalazos.

A propósito de Borges, pero me parece que en mayor medida a partir de Saer y de Piglia — claro que en diálogo con otras literaturas, desde W. G. Sebald a Emmanuel Carrére-, es cada vez más frecuente encontrar en determinados narradores la interrogación constante sobre el acto mismo de narrar. Pero como sabemos, nada de esto es en verdad nuevo.

No veo grandes apuestas formales, asimismo, más allá de la reacción —y a veces la especulación - de recoger ciertos rasgos de la contemporaneidad o la modernidad. Al margen de esos 
gestos a veces superficiales, uno de los ejemplos más interesantes quizá sea el de la novela en sonetos de Pedro Mairal, El gran surubí, no solo — desde luego- por la belleza del texto en sí sino porque establece un diálogo múltiple con lo histórico y lo literario, si es que estas aguas pueden separarse.

2) Cinco palabras: dictadura, parodia, peripecia, inteligencia, timidez.

3) Uno sabe lo que quiso hacer, hasta cierto punto, pero no lo que hizo. Sin que yo lo buscara conscientemente, alguien me dijo hace un tiempo que todos mis libros trataban sobre la amistad, y creo que es cierto. Aunque sin entrar en cuestiones personales, diría que esa búsqueda sin duda se entrevera con una pregunta para mí esencial, y es qué es una familia: cómo atravesar esa experiencia, cómo salir ileso, cómo no lastimar y no salir lastimado.

Por otro lado, trato de seguir a rajatabla aquella idea de que la escritura no embellece a la cosa, sino que es la cosa misma. El estilo — esa palabra tan engañosa o peligrosamente ambigua — se apropia de algo, de un núcleo o un tema o en el peor de los casos un argumento, y lo transforma. Siempre he tratado, y sigo desde ya en esa pelea, de que el qué y el cómo de lo que he escrito se me haga inseparable, inimaginable uno sin el otro.

\section{Félix Bruzzone}

[Nació en 1976, en Buenos Aires. En 2006 fundó con otros autores el sello editorial Tamarisco donde, dos años después, publicó su primer libro de relatos, 76. El título alude al año del golpe del militar de 1976 y también a su condición de hijo de detenidos-desaparecidos. Publicó las novelas Los topos (2008) y Barrefondo (2010). Estudió Letras en la UBA]

1) Mis conocimientos sobre la novelística argentina son bastante limitados como para poder definir semejante situación. Y el límite «a partir de los 90» parece demasiado asociado a eventos políticos cuyos efectos terminaron de apreciarse en forma rotunda recién hacia el final de la década del 90. Siguiendo esta línea, en todo caso, creo que es recién entonces cuando aparecen libros bastante claves: Las islas, de Carlos Gamerro, El terrorista, de Daniel Guebel, y Poesía civil, de Sergio Raimondi. Este último no es una novela, pero... ¿qué cosa no es una novela? Si existe una nueva novela argentina, o algo así, a partir del menemato, habría que ubicarla hacia fines de los 90, y fundada en líneas explícitamente políticas y explícitamente íntimas y explícitamente proliferantes y autorreferenciales y juguetonas. Lo que no podría precisar es en qué medida estas 'novedades's son realmente tales o, más bien, nuevos giros sobre materiales estéticos ya muy trabajados antes. Me atrevo a decir que lo segundo, puesto que si hubo otro elemento que caracterizó al descalabro general de aquella época, eso 
110 | Tropelías. Revista de Teoría de la Literatura y Literatura Comparada, número extraordinario 3 (2018) Encuesta a 18 novelistas

fue la influencia del posmodernismo. Más adelante, quizá, esos elementos se hayan, en cierta forma, estabilizado, dando lugar a novelas más 'ordenadas'. El posible 'renacimiento' de la novela (y la narrativa en general) en las primeras décadas del XXI seguramente responde a cierta voluntad de aplacar aquella proliferación. De ahí que llegando a 2010, y ya entrando en los primeros años de la segunda década del XXI, las novelas de género hayan irrumpido con fuerza. Como si los géneros dejaran de ser un material más para jugar adentro de una novela y pasaran a ser lo que las sostiene desde el primero hasta el último párrafo. Autores como Leo Oyola, o Kike Ferrari. Pero también Carlos Busqued. Parecen polos opuestos, que en otra época hubieran quedado asimilados a literaturas 'menores' y 'mayores', y sin embargo ahí están todos, en diálogo muy directo entre sí, y hasta en el mismo anaquel.

2) Me siento muy tentado de usar las mismas palabras que usa Italo Calvino en sus 6 propuestas para el próximo milenio. Y creo que levedad, rapidez y multiplicidad se mantienen bastante inconmovibles. Visibilidad también, pero no siempre. Y exactitud y consistencia no sé. Creo que, siguiendo un poco con la respuesta anterior, entre las novelas de los 90' en adelante habría que hacer también separaciones. La proliferación y barroquismo y mezcla de estilos que hay en novelistas como Guebel y como Bizzio, en los 90, se convierte (incluso en los mismos Guebel y Bizzio), más adelante, en una especie de retorno clásico. Y, en muchas de las producciones post 2001, en artefactos que dejan el impulso posmoderno y pasan a usar algunas de las formas del posmodernismo para ser, más bien, modernos.

3) Mi trabajo estuvo centrado en encontrarle forma literaria a experiencias demasiado extraliterarias. Hay un rasgo de la literatura, a partir de los 90, que es la autorreferencialidad. Una autorreferencialidad que se dio incluso en autores claramente vitalistas, como Washington Cucurto, o incluso Fabián Casas. En mi caso, que soy un escritor de pocas lecturas (pero repetidas), ese aspecto me resulta poco tentador. El mundo está afuera y la literatura se ocupa de él mucho más que de la literatura que se ocupa de él. Intento que lo 'literario's sea parte de la historia, no del relato. La idea es que en cada libro haya material literario, pero cifrado en la propia retórica, nunca citado, nunca trabajando directamente sobre él. Incluso tomando los materiales de la experiencia del mundo como elementos retóricos. El riesgo de volverse una escritura fundamentalmente temática es grande. Pero la apuesta es siempre un poco esa.

Dentro de esta exploración en la experiencia, me hundí en el llamado 'hijismo', por un lado, y, por otro, en los devaneos del mundo laboral en el que estoy (casi literalmente) inmerso (la limpieza de 
piletas en el conurbano bonaerense) desde hace 14 años. El 'hijismo' sé que seguirá dando algunos frutos. El 'pileterismo' quizá también. Pero no lo sé muy bien todavía.

\section{Gabriela Cabezón Cámara}

[Nació en 1968, en San Isidro, Provincia de Buenos Aires. Como periodista cultural, ha publicado artículos y entrevistas en los diarios Clarín y Página 12, y en las revistas Le Monde Diplomatique, Anfibia, $\tilde{N}$, entre otras. Estudió la carrera de Letras en la UBA. Dicta un Taller de Escritura en la Universidad Nacional de las Artes. Publicó las novelas La Virgen Cabeza (2009, finalista del Memorial Silverio Cañada de la Semana Negra de Gijón), Le viste la cara a Dios (2011) y Las aventuras de la China Iron (2017). En 2013 publicó la novela gráfica Beya, en coautoría con Iñaki Echeverría]

1) Todo lo que puedo decir son impresiones no muy pensadas, no pensé mucho al respecto. Sin lugar a dudas, lo que pasó a fines de los 90 y principios de 2000, fue la irrupción de muchas editoriales medianas y pequeñas. Eso dio lugar a una diversidad muy importante en cuanto a las novelas que se publicaron. Desde entonces, creo, hay una corriente, la de 'la escritura del yo', que se mantiene firme. Apareció, también, una serie de novelas que hacen uso de la oralidad del conurbano. Algunos de los H.I.J.O.S construyeron un imaginario nuevo y muy irreverente de la dictadura y sus consecuencias. También tomó una fuerza particular una corriente de novela rural. Fueron notables varias relecturas de textos centrales de la tradición, como Martín Fierro. Y por supuesto, otro aspecto fundamental fue que las autoras comenzaron a ocupar cada vez más lugar.

2)Interior, Buenos Aires, Conurbano, mujer, yo.

3)Matérico, barroco, barriobajero, lírico, artificioso, político, irreverente, de largas frases espiraladas y llenas de fugas que a veces se muerden la cola.

\section{María Sonia Cristoff}

[Nació en 1965, en Trelew, Provincia de Chubut. Es licenciada en letras por la Universidad de Buenos Aires (UBA). Publicó las novelas Desubicados (2006) y Bajo influencia (2010). Realizó tres antologías, una de escritores patagónicos contemporáneos titulada Geografías literarias: Patagonia (2005), otra de literatura de no ficción escrita por autores iberoamericanos, Idea crónica (2006), y Paisaje a Oriente (2009), que reúne narraciones de viajeros argentinos. En 2005 publicó la crónica Falsa calma (2005)]

1) Para mí hay al menos hay dos buenas novedades en la narrativa argentina a partir de los noventa. Una es la gravitación que empieza a tener la obra de Aira, que ya venía publicando desde la década previa pero que a partir de los noventa empieza a tener algo de faro o, recapitulando algo de una novela 
112 Tropelías. Revista de Teoría de la Literatura y Literatura Comparada, número extraordinario 3 (2018) Encuesta a 18 novelistas

suya que justamente se publicó en 1990, de fantasmal. Porque a César Aira se lo puede tomar como un faro que guía o como un fantasma que acosa o como varias otras cosas más, pero lo que no se puede hacer es negarlo. ¿Por qué? Fundamentalmente porque su obra articula de una manera muy original y consistente algo que había encontrado un punto eximio en Borges y que sobrevuela mucha de la buena literatura argentina: ese gesto doble de narrar y, a la vez, de ir revisando/transformando cuáles son las convenciones que van dando forma a eso que llamamos literatura. Como la articulación de Aira consiste, en gran parte, en generar una maquinaria narrativa proliferante, una especie de reactualización de La Comedia humana que parece surgir no de una "creación artística" sino de un estallido, su obra es un continuo de novelas casi siempre breves, de apariencia banal, de tracción lúdica. Esa operación ha generado efectos colaterales poco felices, es cierto, pero ahora solamente me interesa señalar un efecto más que auspicioso: su contribución a desacralizar la idea de que hace falta escribir La Gran Novela para que una narrativa tenga sustento.

Otra novedad auspiciosa que, desde otro lugar completamente distinto, va en la misma dirección, es el surgimiento de narrativas que buscan en aproximaciones a la hibridez otra forma de arremeter contra esa idea de La Gran Novela (al modo realista/decimonónico). La hibridez no es nueva, como sabemos los que escribimos girando por momentos la cabeza hacia atrás, pero lo que sí son nuevos, o mejor dicho actualizados, en el sentido de transformados, son los modos en los que va operando hoy, los tipos de texto que genera. En líneas generales, y como rasgo general, diría que en estas aproximaciones a la hibridez que empiezan a aparecer en la narrativa argentina a partir de los noventa, y más especialmente a partir de las décadas que les siguen, están presentes un trabajo con lo autorreferencial, un asomo a la no ficción en tanto trabajo con documentos o archivos y una cierta apuesta a lo ensayístico en clave narrativa. Como casos más logrados en esta línea podría mencionar la obra -íntegra - de María Moreno, en la cual todos estos rasgos están trabajados desde las páginas más periféricas del periodismo: la mesa de redacción y la mesa del bar como espacios de formación que permiten una entrada a las lecturas menos canónicas, a las prácticas menos transitadas. También ese libro en el que Osvaldo Baigorria parte en busca de un supuesto antepasado que vivió entre los indios ranqueles para contar una historia on the road con guiños a la novela erótica -Correrías de un infiel (2004) - o su biografía de Néstor Sánchez, uno de nuestros "escritores secretos", en la que Baigorria se va deslizando, muy pausada y justificadamente, hacia la autobiografía, una sombra por encima de otra — Sobre Sánchez (2012). O esos textos en los que Sergio Chejfec va delineando su narrativa documental - Baroni, un viaje (2007) y varios de los relatos de Modo linterna (2013). O las novelas en las que Luis Sagasti va haciendo pie en archivos tan elusivos como sólidos al momento de construir relato - Bellas artes (2011) y Una ofrenda musical (2017). O La biblioteca ideal (2002), ese 
cuaderno de notas el que Matías Serra Bradford va haciendo de las lecturas frondosas y de las amistades precisas dos yacimientos para afilar la mirada, el oído. O El nervio óptico (2014) de María Gainza, un relato que puede leerse como una guía caprichosa de museos — no de museos: de ciertos cuadros muy específicos- de Buenos Aires y a la vez como un vérselas cuerpo a cuerpo con la pertenencia de quien escribe a la clase alta, uno de los tabúes más álgidos de la literatura argentina reciente. O El trabajo de los ojos, en el que Mercedes Halfon hace de sus constantes enfermedades en los ojos una suerte de nouvelle con guiños al cuento de terror. Y también la última obra narrativa de Sylvia Molloy —especialmente Varia imaginación (2003), Desarticulaciones (2010) y Vivir entre lenguas (2016) - en la que el episodio autobiográfico y el ensayo se amalgaman en una prosa que se vuelve impactante en base a elisiones y silencios. Y también los libros en los que Gabriela Massuh entrelaza, a partir de su propia experiencia, la historia de un amor que se termina con un país que parece terminarse también — La intemperie (2008) - y la historia de otro amor con una especie de novela de formación, un Bildungsroman en clave rioplatense — Nací para ser breve (2017). En algún otro momento, en algún otro lugar, sería interesante pensar por qué la mayor parte de estos textos híbridos están escritos por mujeres.

2) Riesgo. Brevedad. Experimentación. Trabajo con la prosa. Autoficción.

3) Hibridez. Entrecruzamiento ficción y no ficción. Narrativa documental. Experimentación. Trabajo con la prosa.

\section{Esther Cross}

[Nació en 1961, en Buenos Aires. Ha publicado tres volúmenes de cuentos y las novelas Crónicas de Alados y Aprendices (1992), La inundación (1993), El banquete de la araña (1999, Premio Nacional de Literatura), Radiana (2007), La señorita Porcel (2008, Premio Internacional de Narrativa, Editorial Siglo XXI, México) y La mujer que escribió Frankenstein (2012). Junto a Félix della Paollera editó dos libros de entrevistas, Bioy Casares a la hora de escribir (1988) y Jorge Luis Borges, sobre la escritura (2007). Tradujo obras de Richard Yates, William Goyen y Mark Twain. En 2004 realizó, junto a Alicia Martínez Pardies, el documental Humillados y ofendidos, sobre el proceso de corrosión del tejido social en Argentina que desencadenó la crisis de 2001]

1) Reconozco tres irrupciones importantes en la narrativa argentina de los últimos años, con consecuencias temáticas y estéticas significativas: la presencia mayor de escritoras, la proliferación de la literatura autobiográfica y el cruce de géneros.

2) Brevedad (y en la misma línea, en el otro extremo, la publicación de la gran novela por parte de algunos escritores). 
114 Tropelías. Revista de Teoría de la Literatura y Literatura Comparada, número extraordinario 3 (2018) Encuesta a 18 novelistas

Diversidad de voces.

Entrecruzamiento de géneros.

Relectura de la historia a través de la ficción.

3) Me resulta muy difícil caracterizar mi propio trabajo por falta de perspectiva y también porque es muy cambiante. Cada texto exige un nuevo planteo. Puedo decir que el trabajo de traductora siempre tuvo mucha influencia en lo que escribo, seguramente porque implica leer con atención extremada un autor y tomar mayor consciencia del propio lenguaje.

\section{Gustavo Ferreyra}

[Nació en Buenos Aires, en 1963. Es sociólogo y se desempeña como docente en la UBA y en bachilleratos para adultos. Ha publicado las novelas El amparo (1994), El desamparo (1997), Gineceo (2001), Vértice (2004), EL Director (2005), Piquito de Oro (2010), Dóberman (2010, Premio Emecé), La familia (2014) y Piquito a secas (2016). Dice Ferreyra en una entrevista con la revista $\tilde{N}$ : «La literatura también está hecha de tiempo, y eso te lo da la novela. Es desde donde ves y percibís la dimensión temporal de la lengua. Y muerde al lector como otros géneros quizá no pueden»]

1) Creo más bien en cierta continuidad en la narrativa argentina de los 90 con respecto a la de la los 80. Sigue desplegándose de alguna manera la transición que la dictadura inicia en el país a mediados de los 70, en concordancia con el auge del neoliberalismo a nivel mundial. Y la impronta cultural que esto supuso.

Se produce una aguda desacralización de las artes y de la salvación a través del arte. Por consiguiente, una pérdida del élan trágico de la literatura. En el país esto podría verse en la fuerte influencia que empiezan a cobrar la literatura a lo Lamborghini y luego a lo César Aira.

Esto cuaja en los 90 en la literatura como broma y/o como parodia. Todo puede leerse en última instancia como parodia; nada debe verse sino como irreal, no verosímil, fantástico, tramposo y, finalmente, antiliterario.

Este aspecto es el predominante, pero como también el sesgo es completamente individualista, se produce una atomización de los autores, un auge del escritor-individuo más o menos aislado. De modo que empieza a regir una diversidad que, lejos de apreciarse en sus bondades, confunde e incomoda a los lectores argentinos, para quienes, luego de Borges, Cortázar y Sábato ya no vale la pena arriesgarse. Para muchos hay ausencia de autores. La crítica de cualquier índole, académica, periodística, etc. cae en un fuerte descrédito. Apenas si Saer y Piglia logran asomar un poco para un pináculo de lectores cultos. 
2) Diversidad, resignación, cinismo.

Aireanos, cools, más clásicos, más vanguardistas, más o menos legibles o lo que fuere que intenten los autores argentinos contemporáneos con su narrativa, hay en general una resignación a la minusvalía de la literatura en el mundo de hoy y en su proyección futura. Lo que lleva a una inevitable modestia pero también al cinismo, a apreciar únicamente la ganancia inmediata. Las ambiciones de obras trascendentes poco menos que se esfuman.

3) Aislamiento, antigualla, retorno.

Más bien asilado de lo que todavía podría llamarse mundillo literario, escribo según los parámetros de la vieja literatura (incluyendo su concepto de vanguardia), esperando un retorno, un ricorsi de la Historia.

\section{Carlos Gamerro}

[Nació en 1963. Es licenciado en Letras por la Universidad de Buenos Aires (UBA), donde ejerció como docente hasta 2002. En 1998 publicó Las Islas, que en 2011 fue llevada al teatro con la dirección de Alejandro Tantanián. A aquella primera novela pronto le siguieron otras, El sueño del señor juez (2000), El secreto y las voces (2002), La aventura de los bustos de Eva (2004), Un yuppie en la columna del Che Guevara (2011) y Cardenio (2016). Ha publicado tres volúmenes de ensayos, El nacimiento de literatura argentina y otros ensayos (2006), Ficciones barrocas (2010) y Facundo o Martín Fierro (2015). En colaboración con Rubén Mira escribió el guión de la película Tres Corazones (2007) de Sergio Renán. Ha traducido textos de Shakespeare, W. H. Auden, Grahan Greene, entre otros autores]

1) A partir de los noventa aparecen una serie de novelas que intentan dar cuenta de períodos complejos como el de la militancia y la guerrilla de los años setenta, la última dictadura y la Guerra de Malvinas, no necesariamente desde la óptica de los actores o ideólogos, como fue habitual durante los ochenta, sino de los 'bystanders' u observadores y, hacia fines de la década, de los hijos de aquellos protagonistas, extendiendo los límites de lo pensable y lo decible. En relación a la Guerra de Malvinas no hay un análogo conflicto generacional, ya que los que la comandaron no hacen literatura $-\mathrm{y}$ su voz no sería oída si intentaran hacerlo- y se convierte en una nueva literatura generacional. Hacia fines de la década empiezan a escribir los jóvenes del decenio menemista: relatos donde prima la sobreactuación de la anomia, del hedonismo vagamente culposo, que achican el espectro a la interacción de jóvenes de un mismo medio y clase social. Y también empiezan a escribir los hijos de los militantes asesinados o desaparecidos, que pertenecen a la misma generación: las dos tendencias, más que confrontar, tienden a ignorarse mutuamente. Estéticamente hay un llamado a regresar a formas narrativas menos experimentales, felizmente desoído por muchos practicantes del género. El mercado latinoamericano manejado desde España, que en los años 60 y 70 elegía promover las novelas más 
116 Tropelías. Revista de Teoría de la Literatura y Literatura Comparada, número extraordinario 3 (2018) Encuesta a 18 novelistas

literarias, ambiciosas y difíciles, a partir de los ochenta se vuelva a los best-sellers, pero a diferencia del mercado anglosajón, que diferencia claramente ambos géneros desde las tapas a los lugares que ocupan en la librería, el español/latinoamericano trata de promover al estatus de gran literatura libros hechos en cadena de montaje para vender mucho.

2) Realismo cotidiano de inspiración estadounidense: sea en la variante sucia (Bukowski y reviente), desempleados/subempleados carverianos (sector de servicios antes que clase obrera), jóvenes menemistas anómicos con plata dados al consumo y a las drogas, y ya en el siglo XXI a las redes sociales y sus virtuales conflictos; habitantes de un degradado mundo Bret Easton Ellis.

Zona de la fantasía: la herencia de Borges, Bioy, Cortázar y Silvina sigue viva en muchos narradores consagrados, y en los intentos más o menos logrados que pueden leerse a carradas, por ejemplo, en los libros presentados a certámenes literarios. El recurso a la realidad virtual, vía el cyberpunk y Philip Dick, y el género terror, se asocian al mismo.

Pura literatura: de impronta mayormente borgeana: desde engordar un texto de Borges a presentar la otra versión de un cuento clásico como «Wakefield» a imaginar la obra perdida de Shakespeare y Flecther basada en el Quijote.

La herencia de la dictadura: ya no focalizada en lo que pasó entonces sino en lo que pasa ahora con sobrevivientes y descendientes. Un género muy propio, no derivativo, tanto como la gauchesca.

3) La crítica y los comentarios suelen usar la palara 'demitificación' para referirse a la manera en que ciertos mitos como las Islas Malvinas, Eva Perón o el Che Guevara son trabajados en mis novelas. Yo prefiero hablar de 'remitificación': no pretendo poner en cuestión o destruir el mito oponiéndola a una supuesta verdad histórica, sino averiguar de qué está hecho el mito en cuestión, y cómo está hecho. Para eso no se me ocurre nada mejor que reconstruir la matriz particular de cada uno, y ponerla a generar nuevos mitos, nuevas variantes: así surgen el videogame de la Guerra de Malvinas en Las Islas; el prostíbulo donde todas las pupilas son versiones de Eva Perón, en La aventura de los bustos de Eva; la fotonovela de la vida del Che filmada en las islas del Tigre, en Un yuppie en la columna del Che Guevara. Estos productos son difíciles de definir como parodia, crítica u homenaje; la razón, creo, es que más bien pretenden ser working models. En esta misma línea trabajo novelas textualmente heterogéneas; me interesa ver como cada género discursivo y cada estilo, en lo que tiene de social y también de individual, conforman la realidad: yuxtaponerlos en el espacio de una sola novela realza la cualidad diferencial de cada uno. 
Encuesta a 18 novelistas

\section{Aníbal Jarkowski}

[Nació en 1960, en Lanús, Provincia de Buenos Aires. Es profesor de Literatura Argentina en la Universidad de Buenos Aires, donde ejerce como docente desde 1985. Ha publicado las novelas Rojo amor (1993), Tres (1998) y El trabajo (2007). Es autor de ensayos sobre Borges, Martínez Estrada, Roberto Arlt, David Viñas, Oliverio Girondo, etc. Ha sido colaborador de las revistas Crisis, Punto de Vista y Variaciones Borges, entre otras]

1) Tengo la impresión de que en la literatura argentina las irrupciones diferenciales más notables y significativas en el sistema literario se producen, no por razones internas, sino externas a ese sistema.

En lo que hace a las novelas escritas en Argentina durante los años 90 tal vez pueda señalarse el progresivo desvanecimiento del patronazgo de Borges, aunque no en términos estéticos sino poéticos, como la desatención a las tramas rigurosas narrativas o la composición de un estilo.

Sin embargo, entiendo que para los años 90 más significativa que la muerte de Borges fue la emergencia de las políticas neoliberales aplicadas durante el menemismo, en estricta obediencia a las recomendaciones de organismos internacionales como el FMI o el Banco Mundial. Esas políticas amorales, desentendidas del bien común, habilitaron algo así como un neoliberalismo novelístico, obediente de las pautas globales del mercado; de ahí que proliferaran escrituras simplificadas sencillas de traducir o editar en mercados distintos del argentino-, cuidadosamente cínicas, temas de interpelación directa al horizonte más amplio posible de lectores y argumentos de actualidad y aspiración de entretenimiento.

De todos modos, más drástica me parece la irrupción diferencial desencadenada por la crisis del año 2001. La situación extrema a la que llegó la sociedad argentina, en términos materiales y simbólicos, impuso el olvido de las diversiones de la década anterior y las novelas —en la medida en que ese género sueña con la representación imaginaria de conjuntos sociales-, tal vez más homogéneas en los temas que en la estética para desarrollarlos, se aplicaron a representar grupos e individuos determinados, en distinto grado, de distintas maneras, por aquella crisis. La marginalidad, por ejemplo, ya no resultó un rasgo socio-psicológico a idealizar, como ocurría en décadas anteriores con 'el loco del pueblo', la prostituta o el niño callejero, sino un componente de la identidad de los personajes en función de causas socio-económicas, como en el caso de las familias cartoneras, los desocupados o los jóvenes sin futuro. Se trató de historias cuyos personajes no hacían una opción por el margen como repudio al sistema, sino que resultaban sus víctimas.

No es extraño, entonces, que esa sociedad quebrada en pedazos diera motivo al culto de identidades acotadas a un barrio, una edad, un imaginario severamente restringido. En términos estéticos eso puede advertirse en lenguas que no quieren ser confundidas con lo literario porque la Literatura, al fin y al cabo, fue cómplice del sistema que produjo la crisis. Casi dos décadas después 
118 Tropelías. Revista de Teoría de la Literatura y Literatura Comparada, número extraordinario 3 (2018) Encuesta a 18 novelistas

esa tendencia, si no estoy muy desactualizado, no se ha desvanecido aunque ha caído en su propia idealización. Las referencias a hábitos y consumos culturales, el recurso a sociolectos y cronolectos, si al comienzo de la crisis fueron estrategias para dar a la luz los desechos sociales que dejó el neoliberalismo, tengo la impresión de que ahora pueden confundirse con haraganerías de la escritura y la imaginación, acomodos a fórmulas que se mostraron eficaces para llamar la atención de la crítica y recibir la aprobación de los lectores; de allí que narradores que comenzaron publicando de manera autogestionada hoy integran los catálogos de empresas transnacionales.

Advierto que no hice referencias a las "literaturas del yo" ni a las narraciones modelizadas en mayor o menor grado por las formas y los lenguajes de las redes sociales; espero que esas y otras muchas faltas me sean disculpadas.

2) Borges is dead.

«Pinta tu aldea y serás universal». ¿Si se pinta la esquina de una cuadra de un barrio también?

Leer es menos valioso que escribir

El cariño del narrador hacia el protagonista — que casi siempre es el mismo y además se parece muchísimo al autor - parece obligar a que todos los demás personajes sean idiotas.

Se tiene la impresión de que hay autores que serían capaces de preguntar: ¿Realmente existían libros antes de que yo naciera?

3) La literatura es lenta, muy lenta.

Ya se escribieron muchas, muchísimas novelas. En cada página aspirar (en secreto) a que lo escrito no avergüence.

Aunque no lo parezca, publicar no tiene nada que ver con escribir.

Lo nuevo es lo contrario de lo actual.

\section{Martín Kohan}

[Nació en Buenos Aires, en 1967. Es profesor de Teoría Literaria en la Universidad de Buenos Aires y en la Universidad de la Patagonia. La pérdida de Laura, su primera novela, fue publicada en 1993. Más tarde dio a conocer El Informe (1997), Dos veces junio (2002), Ciencias morales (Premio Herralde 2007), Cuentas pendientes (2010), Bahía Blanca (2012), Fuera de lugar (2016), entre otras novelas. Es autor de tres volúmenes de relatos breves. Entre sus ensayos pueden destacarse Zona Urbana. Ensayos de lectura sobre Walter Benjamin (2004) y El país de la guerra (2014). Desde hace varios años es columnista del diario Perfil]

1) No me parece que haya habido una irrupción semejante. Lo cual, de por sí, no determina nada, ya que esa clase de irrupciones, la de los cortes con valor de ruptura, se producen muy cada tanto. Tal vez el último que registre la literatura argentina fue la composición de la obra de César Aira (la de muchos 
de sus textos, en parte, y la de su obra como un imposible todo, en especial). Noto, sí, y me interesan, ciertos desarrollos (a los que no creo que quepa otorgar un carácter de irrupción), en cuanto a las formas de abordar cuestiones políticas desde la literatura, por fuera (o hasta en contra) de las tradiciones del compromiso o del realismo.

2) Propongo una: diversidad, que vuelve imposibles a las otras cuatro. Y no en cuanto a que en todo sistema literario existe siempre cierta diversidad, sino en cuanto a que la literatura argentina ha atravesado en estos años un proceso de transformación muy marcado, con la proliferación descomunal de editoriales, la multiplicación exponencial de libros publicados, etc. Lo cual, de por sí, no puede sino suscitar entusiasmo, ya que implicó una generosa ampliación de la circulación literaria; aunque también, hay que decirlo, en ocasiones, una cierta precipitación de publicar por publicar, o un encimarse confuso de unos libros sobre otros, a lo que vino a agregarse el hábito, que no comparto, de que cada escritor se constituya en el agente de propaganda de sí mismo, a golpes de vanidad.

3) ¿Lengua? ¿Forma? ¿Cadencia? ¿Alusión? ¿No dicho? No lo sé.

\section{Alejandra Laurencich}

[Nació en Buenos Aires, en 1963. Ha publicado las novelas Fin de milenio (1994, finalista del Premio Emecé) y Las olas del mundo (2015), además de varios volúmenes de cuentos que posteriormente reunió en Lo que dicen cuando callan (2013). Dicta clases de Escritura de Creativa y es directora de la revista y la editorial $L a$ Balandra]

1) Si bien me cuesta hacer un análisis de la década del 90, ya que en ese tiempo yo misma comencé a producir narrativa, y por tanto, apenas pude ir arrimándome al circuito literario (porque en aquellos años no había en Argentina - como las hubo a partir de mediados de la década siguiente y las sigue habiendo - tertulias literarias para que los autores noveles conocieran la producción de sus colegas, ni editoriales independientes que les dieran cabida incluyéndolos en su catálogo, ya que las pocas que había eran más cercanas a la poesía: Beatriz Viterbo, Último Reino, etc., —y si hubo otras yo las desconocía-), y entre los autores que publicaban en los pocos sellos grandes que editaban literatura nacional y los que recién abordábamos la escritura parecía haber un abismo insalvable, recuerdo que algunas obras me impactaron por su alusión a temáticas de algún modo novedosas y que me eran cercanas: por ejemplo el libro de cuentos de Guillermo Martínez Infierno grande o la novela de Marcelo Caruso, Brüll, entre algunas otras. En ellos, como digo, había una mención clara a los tiempos dictatoriales, a los conflictos de gente que yo podía reconocer como habitantes de esa Argentina en la que estaba viviendo o acababa de vivir, había en ellos cierto rasgo urbano, una cotidianidad, una 
120 | Tropelías. Revista de Teoría de la Literatura y Literatura Comparada, número extraordinario 3 (2018) Encuesta a 18 novelistas

atmósfera reconocible, pero sobre todo el desencanto acerca de la existencia, un tomar conciencia de que había una historia de espanto ocurrida y oculta de la que empezábamos a hablar, aunque fuera así, veladamente, tal como en el cuento de Martínez que le da título al libro que he citado. También yo podía ver el registro de este nuevo modo de decir y nombrar en libros como Bajar es lo peor, de Mariana Enríquez, o los de la colección Biblioteca del Sur, por ejemplo, o algunos textos de la revista Con V de Vian, que llevaban adelante Olguin y Rey, incluso en la novela Santa Evita, de Eloy Martínez, que leí por entregas en el diario Página 12 y se transformó luego en un libro muy vendido. Poco a poco, en otros libros fue consolidándose en mi opinión una mirada que, desde un ámbito cotidiano, doméstico y más bien íntimo, se iba enfocando lentamente en lo que había ocurrido en el país, una mirada que daba cuenta de la crisis económica y existencial, la tremenda herida que nos había dejado la dictadura, una mirada en la que en algunos casos también iba surgiendo el acompañamiento de la música del rock para sus protagonistas, y temas que antes eran más tabúes, como el de la homosexualidad, las drogas, el desprecio por los gobiernos de facto, por los políticos y sus manejos, su corruptela.

Luego, ya en los 2000, todas estas insinuaciones se habían potenciado, y ya para antes de mediados de esa década hubo como una especie de primavera en el ámbito literario que para mí sí representa un antes y un después: los autores que hasta ese momento habían permanecido en sus cuevas comenzaron a unirse, a conocerse, a leer en público, a publicar en blogs literarios, a tomar lugares como propios, a juntarse para formar cooperativas de edición. Surgió una enormidad de sellos independientes que dio luz a una legión de autores que venían escribiendo hacía años pero parecían haber aparecido mágicamente desde cualquier rincón del país. Algunos muy buenos, que hoy son autores reconocidos en el extranjero, pongo el caso de Hernán Ronsino, que empezó escribiendo en blogs y editando una revista en la ciudad del interior en la que había nacido, Chivilcoy. Comenzaron a aparecer antologías de escritores nuevos, muy potentes. Las mujeres como autoras también tuvieron un espacio más importante y destacado. Se publicó la antología Una terraza propia, de Florencia Abatte, en la que figuran los nombres de varias de las autoras que hoy estamos en el mercado, algunas incluso en el mercado internacional. Es decir, que esa primavera literaria dio comienzo o solidez a un fenómeno claramente distinguible: había una nueva narrativa argentina. Sin embargo, junto a una cantidad de buenas novelas y excelentes libros de cuentos, también se fueron publicando obras completamente descartables, porque inscribiéndose en este imaginario de lo íntimo, lo cotidiano, amparados en el derecho a ser publicados, puede creerse que cualquier cosa que uno cuente acerca de su vida diaria es literatura, el comer una salchicha, por ejemplo, o cortarse las uñas, aunque no aporte absolutamente nada a lo que se está relatando. Esto se volvió algo frecuente, mucha, demasiada exposición del yo. 
Otro asunto penoso es que se fue descuidando también en muchos casos la prosa, la elaboración del discurso. Desde la academia quizá sin pretenderlo pareció avalarse este vale todo: no hay géneros literarios, todo puede mezclarse y entonces los autores que no tienen en claro su intención de escritura también pueden refugiarse en estos parámetros: "lo que escribo no es novela ni poesía, es algo que no se puede definir". Es increíble la cantidad de bocetos narrativos que pueden entrar en esta indefinición, aunque una cosa es que el autor tenga una intención deliberada de apropiarse de varios géneros para contar una obra, cosa que considero estupenda, y otra es que un borrador, la primera versión de una obra, con todas sus indefiniciones se publique como si fuera la versión definitiva. También hubo cierto canon que privilegió la novela sin trama, como si una buena historia con un argumento sólido y atrapante fuera de por sí algo censurable. Quiero decir, que hay una especie de confusión generalizada que venimos abonando, y que no sólo fueron esos libros publicados por grupos de amigos que se juntaron a editarse entre sí los que le hicieron un poco de daño a la literatura, puesto que en gran parte de lo editado ya dejó de haber criterio, hay poca corrección previa de lo que se da a conocer, hay poco acabado estético. El vale todo, el "también yo tengo un libro publicado", se han convertido en plaga. Hoy creo que hay más libros que lectores, más gente que escribe que escritores. Hay que leer mucho para encontrar algo verdaderamente genuino y potente, y eso agota a cualquiera. Quizá ahora faltaría un volver a replantearse si todo lo que se escribe vale la pena de ser publicado, algo que en cualquier sentido es una buena práctica para el escritor.

2) No creo que haya caracterización válida, hay una inmensidad de propuestas en todo ese corpus de publicaciones que menciono en el punto anterior, imposible señalar una característica común, más allá de las expuestas anteriormente, pero si tuviera que individualizar una de las más llamativas (no por su valor sino por su reiteración) es la de las distopías como argumento. Pareciera que ahora muchos autores quieren parecerse a Margaret Atwood. O quizá sea una muestra de lo que teme esa mayoría silenciosa de la humanidad y que termina expresándose en la obra de un escritor que la capta y la traduce literariamente. Por ahora tiene aspecto de figurita repetida que empieza a cansar, una moda.

3) Tampoco tengo opinión formada sobre mi propia obra, pero viéndome forzada a encontrar algo que los caracterice podría señalar que uno de los asuntos sobre los que me interesa indagar es la interioridad de los personajes, sus conflictos más íntimos, su lucha diaria y solapada por la supervivencia en un mundo tan tremendamente hostil como es el nuestro. No sólo en protagonistas mujeres, aunque un sesenta por ciento de mis libros las muestra como personajes centrales. 
Y otro punto que ya algunos han señalado como característico, es la alusión frecuente a la música, desconozco las razones por las que incluyo frecuentemente menciones a la música, desde el rock a los conciertos barrocos o las composiciones medievales, pero esto puede ser una característica a anotar.

\section{María Rosa Lojo}

[Nació en 1954, en Buenos Aires. Es doctora en Letras por la UBA y desempeña como investigadora principal del CONICET. Es profesora de posgrado en la Universidad del Salvador, donde además es directora del CECLA (Centro de Estudios Críticos de Literatura Argentina). Dirige la Colección EALA (Ediciones Académicas de Literatura Argentina). Ha publicado más de veinte volúmenes pertenecientes a distintos géneros, entre ellas las novelas Las Libre del Sur (2004), Finisterre (2005), Árbol de familia (2010) y Todo éramos hijos (2014), solo para mencionar las cuatro más recientes. En 2017, ha editado junto a Enzo Cárcano el volumen Leopoldo Marechal y el canon del XXI, publicado por la Universidad de Navarra]

1) Aunque Borges nunca publicó una novela, creo que su ausencia física en la década del '90, después de haberse convertido en un autor del canon universal, fue un hecho decisivo para todos los narradores argentinos. El neo kitsch de Manuel Puig, la deliberada 'mala literatura' de César Aira, el insolente punk de Rodolfo Fogwill, el 'realismo delirante' de Alberto Laiseca, entre otros nombres, ya se habían desmarcado de la pauta borgeana y otros los seguirían. No digo tanto 'otras' porque me parece que la 'angustia de las influencias', como modelo o antimodelo, ha tocado más a los escritores varones que a las mujeres. Como, de entrada, las escritoras argentinas no estaban 'de ofició incluidas en ningún canon (salvo a manera de la excepción que confirma la regla), me parece que - contraparte beneficiosa—, se sintieron con más libertad para escribir.

A propósito, creo también que en las últimas tres décadas y media se han multiplicado las narradoras, en todos los géneros y modalidades y desde muy diversas vertientes estéticas: esta es una gran noticia, sin duda alguna.

¿Novedades en la escritura? Por un lado, los antiguos modos ficcionales narrativos siguen existiendo, pero con inflexiones particulares. El policial florece, más negro que nunca (Saccomanno, Olguín). El fantástico, con su larga tradición rioplatense, desemboca en narrativas del extrañamiento extremo (Schweblin), o del horror/terror (Enríquez). O, en sintonía con fenómenos mundiales (el revival del fantasy), surgen sagas épicas marcadas por lo mítico-maravilloso, como la obra de Liliana Bodoc.

La novela histórica (fundacional para la narrativa argentina) adquiere primero (en los '90), más allá de las distancias estéticas entre los autores, ciertas tematizaciones comunes, que pasan por dotar a los héroes/próceres de un cuerpo sujeto a la debilidad y la decadencia así como de una intimidad sexual y sentimental; las mujeres y las etnias y culturas no blancas, subalternas, reaparecen, por su parte, 
como los sujetos, agentes o víctimas silenciadas de la Historia: desde Andrés Rivera a María Esther de Miguel, desde Eduardo Belgrano Rawson a Sylvia Iparraguirre. Ya en el siglo XXI emerge una modalidad diferente: la novela erótico-sentimental de fondo histórico, representada por Florencia Bonelli y otras autoras.

En relación con los debates de la Historia y de la política surge y se refuerza en las últimas décadas una 'narrativa de la memoria histórica', que atañe al terrorismo de Estado, a la insurgencia armada y sus preliminares, a la última dictadura militar, a la Guerra de Malvinas. Sus autores van desde aquellos que vivieron todos estos procesos hasta los hijos de los desaparecidos (de José Pablo Feinmann a Félix Bruzzone o Laura Alcoba, entre otros). Muchas veces esta narrativa es 'autoficcional' pero otras veces no, como sucede con libros de Martín Kohan (Dos veces junio, por ejemplo). La 'autoficción'en sí misma, más allá de la temática, puede considerarse como una marca escritural de época que empieza a proliferar a partir de los '90. También reviven formas tradicionales de las 'escrituras del yo' como los diarios (baste pensar en Piglia o en Abelardo Castillo). Como fenómeno del siglo XXI hay que destacar la emergencia de las "novelas de la villa" (entendiendo ahora la 'villa' como peculiar universo cultural), caracterizadas por una estética del exceso, o un neorrealismo sobrecargado, con autores como Cabezón Cámara, Oyola, etc. También nuevas miradas se focalizan en el área del conurbano, desde la zona de clase baja o media baja, popular (Incardona) hasta los countries (Piñeiro).

2) La heterogeneidad de poéticas dificulta encontrar palabras que permitan una caracterización general. Si es por modalidades ficcionales dentro de la novela ya me he referido a ellas: novela policial, histórica, de la memoria, autoficcional, erótico sentimental, épico-maravillosa, fantástico-extraña. Pero me animaría a considerar ciertos ejes problemático/temáticos que de algún modo atraviesan toda la novelística: Violencia social, construcción del poder, subjetividades, subalternidades, pasiones, tensión utópico-distópica.

3) Si es por las tematizaciones recurrentes: identidad, (in)migración, exilios, memoria, subalternidad, desconstrucción de estereotipos étnicos y genéricos, desarticulación del pensamiento dicotómico, relaciones problemáticas tanto entre generaciones (padres e hijos) como con lo sagrado (el gran 'Padre' judeo-cristiano). Si es por las modalidades ficcionales, creo que la hibridación genérica y la transfiguración poético-simbólica son mis constantes.

Empecé a publicar en los '80, y lo hice con la poesía (poema en prosa), antes que con la narrativa. Desde los '90 publiqué una serie de novelas específicamente vinculadas a la historia de la Argentina, a los personajes, sucesos y procesos que la marcaron y determinaron nuestro presente: La pasión de 
124 | Tropelías. Revista de Teoría de la Literatura y Literatura Comparada, número extraordinario 3 (2018) Encuesta a 18 novelistas

los nómades (1994), La princesa federal (1998), Una mujer de fin de siglo (1999), Las libres del Sur (2004), Finisterre (2005). Otras, aunque traspasadas por la Historia, tienen una orientación autobiográfica y/o autoficcional, más allá de un sujeto biográfico empírico, y se extienden a una familia (potencialmente representativa de muchas), o a toda una generación. Así sucede con la opera prima Canción perdida en Buenos Aires al Oeste (1987), con Árbol de familia (2010) y con Todos éramos hijos (2014). Suele haber en estas novelas una fuerte mirada desde las mujeres, que pone en relieve tanto los condicionamientos históricos de la posición femenina, así como la voluntad de ruptura, con sus contradicciones, complejidades, avances y retrocesos.

Creo que mis libros son en general difíciles de 'etiquetar', Pienso en las 'brevedades' líriconarrativas de Bosque de ojos, en Cuerpos resplandecientes (con su deliberada mixtura de ficción y ensayo, que también se da en otros libros de cuentos como Historias ocultas en la Recoleta y en Amores insólitos). La princesa federal combina las estrategias del reportaje, la sesión de psicoanálisis y el diario íntimo, con una visión lírica, que es la perspectiva predominante en Una mujer de fin de siglo. La reflexión ensayística, la lectura del canon literario argentino a contrapelo están muy presentes en Las libres del Sur. Árbol de familia: ¿es novela o corpus de relatos breves enlazados por el hilo tenue de una narradora que se esconde? El Libro de las Siniguales y del único Sinigual, ¿es para niños o para adultos? Sus textos, ¿son micrrorelatos o poemas? La pasión de los nómades, ¿pertenece a la ficción histórica o a la maravillosa? ¿Qué es Todos éramos hijos: memoria, ficción, autoficción, novela histórica?

La erosión de todas las dicotomías, apoyada en la voluntaria hibridez genérica, en los incesantes cruces, me sitúa siempre en un borde (así lo definió Marcela Crespo Buiturón), una frontera, un 'corredor' en todos los sentidos (símbolo central en Árbol de familia, novela de la migración por excelencia). Es una posición bastante incómoda. Porque busco la totalidad, la mirada poliédrica, la conjunción, la iluminación coral. Pero corro siempre el riesgo de que no vean el 'y' sino el 'ni', en casi todos los planos. Al final, dirán o dicen algunos, esta, ¿quién es?, ¿qué hace?: ¿argentina o gallega?, ¿creadora o crítica?, ¿poeta o prosista?, ¿'civilizada' que reivindica a los 'bárbaros’?, ¿posmoderna o antigua?, ¿erudita que apela también a formas de la cultura popular?, ¿atea o creyente?, ¿memorialista o novelista?, ¿historiadora o narradora? ¿Dónde la pongo, cómo la leo? Con todo, lo importante no es que los libros se definan, sino, como decía Horacio (el viejo) que encuentren sus destinos (sus lectores).

\section{María Pía López}

[Nació en 1969. Publicó las novelas No tengo tiempo (2010), Habla Clara (2010), Teatro de Operaciones (2014) y Miss Once (2015). Como ensayista ha dado a conocer Mutantes. Trazos sobre el cuerpo (1997), Sábato o la moral de los argentinos (1997, escrito en colaboración con Guillermo Korn), Lugones. Entre la aventura y la cruzada (2010) y Hacia una la vida intensa. Una historia de la sensibilidad vitalista (2010). Fue miembro de 
los grupos de editores de las revistas El Ojo Mocho y La Escena Contemporánea. Es profesora en la Facultad de Ciencias Sociales de la Universidad de Buenos Aires. Desde 2012 a fines de 2015 fue directora del Museo del Libro y de la lengua, de la Biblioteca Nacional]

1) En la zona de las narrativas que toman el terrorismo de Estado, se produce un tajo. Tiene que ver con una renovación generacional (ya no escriben los que pertenecen a la generación de los detenidos desaparecidos, sino la de sus hijos) y con una transformación en el campo literario. Si en la década de 1980 primaba el vínculo con el testimonio y la denuncia, después del 2000 aparecen obras como Los topos de Félix Bruzzone o Diario de una princesa montonera, de Mariana Pérez, que incluyen humor en la narrativa vinculada a las desapariciones. Entre ambos polos, Las islas, de Gamerro, es una suerte de monstruo que apela tanto a la risa como a la multiplicación de las citas de las narraciones existentes sobre Malvinas.

Por otro lado, la ciudad de Buenos Aires y su conurbano se afirman como dispositivo narrativo, que sostiene extraordinarias ciudades ficcionales. Sucede en la obra de César Aira, como La villa, donde las referencias a la ciudad real son el camino para la construcción del realismo delirante. Pero también en las novelas de Sergio Chejfec, como El aire o Los planetas, donde la ciudad es a la vez reconocible y absolutamente ficcional. Y en El dock, de Matilde Sánchez, acentuado por el vínculo con un acontecimiento datado. El efecto se complejiza aún más en la literatura de Marcelo Cohen, donde la ciudad ficcional implica otro tiempo y otro léxico. Esas variantes del realismo, donde se conjuga con ficciones muy potentes, que brillan justamente en la reminiscencia de la ciudad real que provocan en el lector y la desmentida permanente de esa reminiscencia.

Lo plebeyo, lo popular, aparecieron, cada vez con más fuerza, y vinculados a un cuerpo sexuado. Contra la literatura de la lengua culta, se despliega una apelación a la oralidad popular, a la dislocación gramatical, y la sexualidad explícita. Las novelas de Washington Cucurto o Alejandro López hacen esto. Las modificaciones en el campo social de qué es posible decir están vinculadas a esta serie.

Finalmente, el proceso de estallido de las fronteras entre géneros coexistió con otro, que es de la afirmación de la narración novelística. Apareció una serie de escritores, marcados generacionalmente (Martín Kohan, Miguel Vitagliano, Aníbal Jarkowski, Gustavo Ferreyra) con obras de factura clásica y precisión narrativa. En general se menciona la irrupción de los escritores de Babel, pero los efectos en el campo literario provienen más claramente de esta generación.

2) Ritmo. Relatos que suenan, escrituras que alojan la poesía al interior de la narración, detenidas en el lenguaje, enamoradas del lenguaje. La reja, de Matías Alinovi, toma la estructura del endecasílabo para narrar. Las novelas de Hugo Savino, de Liliana Heer o de Américo Cristófalo hacen estallar la 
126 Tropelías. Revista de Teoría de la Literatura y Literatura Comparada, número extraordinario 3 (2018) Encuesta a 18 novelistas

narración para arrojar fragmentos sonoros. Las de Gabriela Cabezón Cámara afirman una lengua rítmica.

Ficción. La ficción más allá del género, poniendo en crisis las fronteras del género. Mezclando novela y crónica, ensayo y novela, ensayo y biografía. Pienso, por ejemplo, en Piletas de Bruzzone, Redacciones cautivas, de Horacio González, Sobre Sanchez de Osvaldo Baigorria, Confluencias, de Inés Kreplak.

Yo. Parte de ese dispositivo ficcional que desborda los géneros, es la construcción del yo. Narrar la experiencia propia como modo de comprender una época, El diario. Los diarios de Emilio Renzi, obra final de Ricardo Piglia, Black out de María Moreno, son ejemplos excepcionales. No son diarios de escritores ni memorias, sino construcciones del yo escritor a la vista del lector, mostrando los procedimientos ficcionales y a la vez encubriéndolos.

Travesía. Las novelas donde la fuerza del deseo, casi anónima, ignorada por los propios personajes, producen las peripecias. Así las novelas de Ariana Harwicz, Mariana Dimópulos, Carla Maliandi, narran modos de la experiencia femenina, centradas en la opacidad del deseo.

Narración. Se actualizan las formas narrativas, sobre la base de tradiciones clásicas. Eso no significa conservadurismo, sino puesta en juego de una lengua muy elaborada y con capacidad de contar historias, como sucede en El viento que arrasa, de Selva Almada, en Glaxo de Hernán Ronsino, en Hospital Posadas, de Jorge Consiglio.

3) Lengua. En el primer plano, está la cuestión de la lengua, pensada como experimentación y sonoridad. En especial, Miss Once y No tengo tiempo.

Sonoridad. Son novelas leídas en voz alta, murmuradas, no escritas en silencio. Importa el ritmo.

Cuerpo. El tema recurrente es el cuerpo. No solo en las novelas. Desde el primer libro de ensayos, Mutantes. Trazos sobre el cuerpo, hasta el último Yo ya no. Es el cuerpo como lengua, el cuerpo desposeído en el deseo, el cuerpo atravesado por el tiempo. 
Tiempo. Hay novelas morosas — como Habla Clara — y otras agitadas —No tengo tiempo-. Se trata menos de narrar sobre el tiempo que de materializar el tiempo en la escritura.

\section{Germán Maggiori}

[Nació en 1971, en José Mármol, Provincia de Buenos Aires. En 2001, publicó su novela Entre hombres, que obtuvo el primer premio del concurso Resistencia, en México. Ha participado en distintas antologías de narrativa, entre las que se destacan La joven guardia. Nueva literatura argentina, realizada por M. Tomas, y Fieras. Antología del género policial en Argentina, a cargo de Ricardo Piglia]

1) Diría que justamente en esa época, a principio de los noventa, hubo un intento - a mi entender fallido - de irrupción de una nueva estética motorizada por los escritores que se nucleaban en torno a la revista Babel, los del grupo 'Shanghai', una movida que venía fogoneada desde la academia y que contaba además con la complicidad de los suplementos culturales. El capricho antirrealista, el autorreferencialismo, el exotismo de los escenarios y el disparate argumental que uno encuentra en estas novelas acotó su circulación al puñado de 'iniciados' que comulgaban con sus teorías. Esa línea aún hoy cuenta con algunos seguidores que repiten lo que ya Aira viene repitiendo en vaya uno a saber cuántos libros.

También por esos años, salió la colección Biblioteca del Sur, dirigida por Juan Forn que a pesar de terminar siendo un poco irregular tuvo la genuina virtud de empezar publicando autores jóvenes, que contaban efectivamente historias, con una lengua ágil, bien posmoderna. Novelas y cuentos muy bien estructurado que incluso se permitían experimentar en el marco de géneros considerados marginales. El mal menor de Charlie Feiling es tal vez la novela más notable de esa serie.

No obstante estar parados en veredas diferentes, ninguno de los dos grupos, ni los Shanghai ni los autores jóvenes de Biblioteca del Sur, se hicieron cargo de procesar la evidente derrota cultural que había dejado la dictadura militar y señalar los estragos del neoliberalismo. Ese tópico se cuidaron de evitarlo. El primero, y tal vez el único, de esa generación que se atrevió a conjurarlo, diría que fue Salvador Benesdra con El traductor. Su muerte, tirándose al vacío desde un décimo piso en una crisis depresiva, es una imagen sobrecogedora que se me figura como el correlato perfecto de esa cuenta cuyo saldo se había diferido hasta la exasperación y la locura.

2) Es difícil responder esto por lo mismo que explicaba antes, la nuestra es una tradición que está siempre escindida, pareciera ser que siempre estamos lidiando entre al menos dos bandos y entonces es muy difícil, o para mí es difícil, encontrar cinco conceptos que no se contradigan y que sean al 
mismo tiempo característicos de las novelas argentinas contemporáneas en el marco de un corpus que es tan heterogéneo.

3) Genialidad, originalidad, maestría, irreverencia, ... je je, no hay forma de responder honestamente esta pregunta.

\section{Natalia Moret}

[Nació en 1978, en Buenos Aires. En 2012 publicó su primera novela, Un publicista en apuros. Ha participado en distintas antologías de relatos breves, como Nuevas narrativas. Historias breves II (2006), Buenos Aires Escala 1:1 (2008) y Outsider (2011)]

1) Creo que surgieron muchos autores y novelas que sitúan sus historias en los márgenes de la sociedad, tomando como protagonistas antihéroes surgidos de las clases sociales postergadas, con la pobreza como geografía y la nostalgia de los años dorados del peronismo como música de fondo, que crean universos de pobreza estetizada, romantizada. Algo parecido a un 'orgullo villero' literario, emulado por autores que generalmente provienen de clases medias, educadas, privilegiadas. El trasfondo es una corrección política más o menos autoconsciente, síntoma creciente de una época estética y políticamente afín a las minorías, una corrección política que sabe (con mayor o menor talento para la ironía, la sutileza y la complejidad) dónde está el bien y dónde el mal: el primero en los muchos de abajo, el segundo en los pocos de arriba. Esta irrupción para mí empieza germinalmente en los noventa, tal vez en parte como reacción al menemismo (su exaltación de la frivolidad, del consumismo, de la prepotencia barata de los nuevos ricos) y en parte por los tiempos que marca la moda (cada treinta años, lo que se usaba entonces vuelve de forma renovada, recuperada y reeditada por las vanguardias; de ahí la apropiación estética del ideario peronista); se intensifica en los dos mil y, podríamos decir, llega al poder de mano del kirchnerismo, que explota de forma muy eficaz, al menos en los primeros años, esa comunión entre la fealdad villera y la belleza del progresismo más sofisticado. Ahí, creo yo, hay una clave temática y estética para leer la novela argentina de los noventa a hoy que, creo, actualmente se encuentra ya en retirada.

En paralelo, y creo que en oposición a esta literatura de lo 'barrial' que se excita más y más cuanto más mugrosa sea, existe otra corriente en la que se inscriben muchas novelas y autores cuya búsqueda va más por la forma: una literatura mínima, higiénica, fría, de prosa que equipara elegancia a economía de recursos y trama casi invisible (o inexistente) como vehículo para la representación de la clase media desganada y anodina en la que sitúan casi todas sus historias y personajes. 
2) Pensando en lo que se escribe en los últimos cinco años:

Breves, cada vez más breves; de hecho, hubo una especie de boom de la nouvelle y el año pasado y el anterior se publicó una gran cantidad de muy buenos libros de cuentos, algo para nada usual. Con un interés renovado en las historias, las tramas (excelente noticia), las cuestiones de género y el ascenso del feminismo, cada vez más escritas y protagonizadas por mujeres.

3) Lo que me preguntás es muy difícil, no tanto de decir, pero sí de entender cuando se trata del trabajo propio. Se me ocurren algunas palabras clave que, me parece, están presentes de alguna forma en lo que escribo. En el universo, en los temas, en los personajes. No sé si están en lo que en efecto escribo, pero seguro lo están en los planes, en lo que intento escribir. Me interesan los conflictos y la tensión que existe en los personajes que se sitúan en los bordes. Los que ya no pertenecen al lugar del que vinieron pero todavía no encuentran un lugar al que llegar. Los que no pertenecen. El extranjero, el apátrida. Los desclasados. Los que mejoraron o empeoraron pero siempre son distintos al clan del que se salieron: la familia, los amigos, las redes. No tienen. Las perdieron. Me interesan sobre todo los que fueron excluidos de la pobreza, los que ascendieron y por eso ya no son dignos en los lugares donde se los supo querer en la infancia. Ya no son bien recibidos. Son, a la vez, motivo de orgullo y vergüenza. Los personajes que son una decepción para 'los suyos'. Me interesa su sufrimiento, su resentimiento y las distintas formas posibles de su venganza y de su felicidad. La movilidad social y el derrumbe social, las expectativas y la consecuente frustración. La falta de redes y contención como motor para la aparición de los humanos 'hechos a sí mismos'. Los self made. Los solos contra el mundo.

\section{Ana Ojeda}

[Nació en 1979, en Buenos Aires. Publicó las novelas Modos del asedio (2007), Falso contacto (2012) y No es lo que pensás. Sobre la imposibilidad de viajar (2015), y los cuentos reunidos en Necias y nercias (2017) y La invención de lo cotidiano (2013). Es traductora y dirige el sello editorial El 8vo.Loco]

1) Creo que la llamada 'literatura del yó es el aporte de los 90-2000 a la narrativa rioplatense urbana. Explora vínculos (amorosos, amistosos) en espacios acotados, que pueden se simbólicos (p. ej., la familia) o reales (una casa, una habitación, una ciudad). Es una literatura de la cotidianidad, que funciona sobre el presupuesto de Tolstoi de 'pinta tu aldea y pintarás el mundo'. El intento de narración total (de una época, de una generación) va cayendo en desgracia frente a narraciones mucho más 
130 | Tropelías. Revista de Teoría de la Literatura y Literatura Comparada, número extraordinario 3 (2018) Encuesta a 18 novelistas

breves, fragmentarias, modestas en sus aspiraciones: ya no reflejar el mundo, sino apenas una astilla de él. Aparece la literatura del conurbano, con la construcción de arquetipos relacionados con la delincuencia, la droga, etc. Se afianzan los relatos con personajes femeninos que rechazan las imposiciones sociales para el género: mujeres que no quieren ser madres o esposas o lindas, es decir, que se niegan a integrar el estereotipo.

Washington Cucurto retoma la picaresca (hilo rojo que podemos seguir hasta la década del veinte de Roberto Arlt o Enrique González Tuñón) con historias que transcurren en el conurbano y una búsqueda interesante a nivel del lenguaje.

\section{2) Brevedad fragmentaria}

Auge de los géneros: ciencia ficción, fantástico, terror, etc.

Uso del lenguaje establecido como código común.

Petite histoire.

3) Lenguaje intervenido (deforme)

Alteración de la sintaxis. Humor. Ridículo. Grotesco. Reír para no llorar. Cambalache. Inmigración. Mujeres.

\section{Luis Sagasti}

[Nació en 1963, en Bahía Blanca. Es crítico de arte y docente. Publicó el ensayo Perdidos en el espacio (2011) y las novelas El canon de Leipzig (1999), Los mares de la luna (2006), Bellas artes (2011), Maelstrom (2015) y Una ofrenda musical (2017)]

1) No sabría precisar en qué momento de la década pero claramente creo que se produce una suerte de quiebre, por llamarlo de algún modo, a partir de ciertas publicaciones o decisiones editoriales como fue la colección de Planeta Biblioteca Sur. Desde allí se advierte un regreso al relato puro en detrimento de cierto tipo de apuesta más cercana a la formalidad. No es casual que en ese entonces se baje de la estantería a Cortázar, por ejemplo, y comience la difusión —y torrencial publicación— de César Aira. Al mismo tiempo, y de la mano con la crisis de los grandes relatos, las ambiciones y aspiraciones de una novela que sea un cosmos fueron reemplazadas $-\mathrm{y}$ muchas veces con un aliento norteamericano allá Carver o Cheever- por historias que son haces que echan una luz fugaz sobre los grandes temas. De todos modos, considero que hay un regreso a cierto formalismo y una manera distinta de narrar, a partir de la segunda mitad de la década pasada impulsada por las nuevas tecnologías cuyas 
características más salientes en el tratamiento de las tramas las enumero en la pregunta siguiente, pero creo que se engloban todas en torno a la idea general de una crisis de la linealidad del relato.

2) Fragmentación, discontinuidad, simultaneidad, apropiación, yuxtaposición.

3) Alguno de los citados arriba. Acaso la fragmentación y yuxtaposición de muchas historias y la simultaneidad de géneros — que no busco voluntariamente - con que trabajo. Una tercera idea muy importante para mí es la de tomar la información pura como poesía. Quiero decir encontrar tensiones poéticas en el dato puro y duro. El hecho de que el río Amazonas no sea atravesado por ningún puente en sus casi 7000 kms., es un claro ejemplo, para mí. 